\title{
Thinking Structurally: A Cognitive Framework for Understanding How People Attribute Inequality to Structural Causes
}

\author{
Jamie Amemiya ${ }^{1}$, Elizabeth Mortenson ${ }^{2}$, Gail D. Heyman ${ }^{1}$, \& Caren M. Walker ${ }^{1}$ \\ ${ }^{1}$ Department of Psychology, University of California, San Diego \\ ${ }^{2}$ Department of Psychology, Stanford University \\ In press at Perspectives on Psychological Science.
}

\begin{abstract}
Author Note
We are grateful to the anonymous reviewers, the Early Learning and Cognition Lab, the Social Cognitive Development Lab, Lin Bian, Brian Donovan, Daphne Henry, and Nabila Jamal Orozco for their thoughtful feedback. The writing of this article was supported by the Eunice Kennedy Shriver National Institute of Child Health \& Human Development of the National Institutes of Health under Award Number F32HD098777 awarded to Jamie Amemiya. The content is solely the responsibility of the authors and does not necessarily represent the official views of the National Institutes of Health. Please address correspondence to Jamie Amemiya, Department of Psychology, University of California, San Diego, 9500 Gilman Drive, La Jolla, CA 92093-0109. Phone: (925) 998-2555. Email: jamemiya@ucsd.edu
\end{abstract}




\begin{abstract}
To make accurate causal inferences about social group inequalities, people must consider structural causes. Structural causes are a distinct type of extrinsic cause - they are stable, interconnected societal forces that systematically advantage some social groups and disadvantage others. We propose a cognitive framework to specify how people attribute inequality to structural causes. This framework is rooted in counterfactual theories of causal judgment and suggests that people will recognize structural factors as causal when they are perceived as "differencemaking" for inequality above and beyond any intrinsic causes. Building on this foundation, our framework makes the following contributions: First, we propose specific types of evidence that support difference-making inferences about structural factors, within-group change (i.e., the disadvantaged group's outcomes improve under better societal conditions) and between-group comparisons (i.e., the advantaged group, who has similar baseline intrinsic traits to the disadvantaged group, experiences more favorable societal conditions and outcomes). Second, we consider contextual, cognitive, and motivational barriers that may complicate the availability and acceptance of this evidence. We conclude by exploring how the framework might be applied in future research on people's causal inferences about inequality.
\end{abstract}

Keywords: inequality; causal attribution; structural causes 


\section{Thinking Structurally: A Cognitive Framework for Understanding How People Attribute Inequality to Structural Causes}

Structural causes of inequality are stable, interconnected societal forces that systematically advantage some social groups and disadvantage others (Bonilla-Silva, 2015; Carmichael \& Hamilton, 1967; Crenshaw, 1989; Haslanger, 2016; Hatzenbuehler, 2016; Jones, 1997; Rucker \& Richeson, 2021; Salter et al., 2018). Research across the social sciences has documented how structural factors - which include societal institutions and cultural beliefscontribute to inequalities in life outcomes between racial (Cooley et al., 2020; Hoffman et al., 2016; Lawrence \& Mollborn, 2017; Pierson et al., 2020; Reece \& O’Connell, 2016), gender (Bian et al., 2018; Cheryan et al., 2017; Herd et al., 2019; Leslie et al., 2015; Yavorsky et al., 2015), socioeconomic (Browman et al., 2019; Duncan et al., 2017; Kraus, Torrez, et al., 2019; Laurin et al., 2019; Phillips et al., 2020), and LGTBQ (Hatzenbuehler et al., 2010; Raifman et al., 2017) groups, and can be exacerbated at their intersections (Cole, 2009; Crenshaw, 1989; Henry et al., 2020; Lei \& Rhodes, 2021; Purdie-Vaughns \& Eibach, 2008; Sidanius et al., 2018).

Despite this fact, people often fail to acknowledge structural causes of inequality. Instead, many people favor intrinsic explanations that emphasize traits like ability or motivation (Cimpian \& Salomon, 2014; Hunt, 2007; Kluegel \& Smith, 1986; Mistry et al., 2012; Sigelman, 2012) or essentialist explanations that assume fixed innate differences between groups (DarNimrod \& Heine, 2011; Donovan, 2016; Panofsky et al., 2021). Although intrinsic factors may mediate structural influences, it is problematic to treat them as the sole root causes of inequality or as immutable properties (Cheryan et al., 2017; Donovan et al., 2019; Hetey \& Eberhardt, 2018; Laurin et al., 2019; Rucker \& Richeson, 2021; Spelke, 2005). 
In addition to its importance for understanding human difference, recognizing structural influences has implications for how people reason about social policy and intervention.

Disregarding structural causes can lead to false conclusions, such as assuming that individuals are solely to blame for their disadvantage, or that societal interventions will have no effect for some groups (McCoy \& Major, 2007; Piff et al., 2020; Rucker \& Richeson, 2021; Soylu Yalcinkaya et al., 2017; Weiner et al., 2011).

Given the importance of acknowledging structural causes, a critical question becomes: How do people attribute inequality to structural causes? While research has focused on people's ignorance of or motivation to reject information about structural factors (Cimpian \& Salomon, 2014; Jost, 2019; Rucker \& Richeson, 2021), less work has detailed how people successfully make this causal link. In the present article, we present a cognitive framework, the differencemaking framework of structural causal attribution, to describe this inferential process.

We organize the paper as follows. First, we describe the central issue: The causes of inequality are not readily apparent, and people can infer different causes, namely intrinsic or structural. Second, we outline our framework, which is rooted in counterfactual theories of causal judgment and posits that people infer structural causes if they perceive that structural factors were "difference-making" for inequality above and beyond any intrinsic causes. Third, we propose specific types of evidence that support structural causal attribution, and critically, contextual, cognitive, and motivational barriers to the availability and acceptance of this evidence. We conclude by outlining future research directions.

\section{Making Sense of What Causes Inequality}

People start noticing inequalities between social groups early in life (Rhodes \& Baron, 2019; Santhanagopalan et al., 2022; Shutts, 2015). For example, by at least 5 to 7 years of age, 
children are aware that White people tend to be wealthier than Black people (Elenbaas \& Killen, 2016; Mandalaywala et al., 2020; Olson et al., 2012), that men tend to hold higher status occupations than women (Liben et al., 2001; Miller et al., 2018), and that people of high socioeconomic status tend to have more desirable possessions (Dore et al., 2018; Peretz-Lange et al., 2022).

However, even when people agree that there is inequality, they may still disagree about its causes (Hetey \& Eberhardt, 2018; Mijs, 2018; Peretz-Lange et al., 2021; Vasilyeva et al., 2018; Vasilyeva \& Lombrozo, 2020). For example, in judging why there are more men than women in the field of engineering, one person may favor structural causes that are extrinsic to the groups (e.g., men have more societal support than women to participate in the field), while another person may privilege intrinsic causes (e.g., men are inherently smarter than women at math; see Dennehy \& Dasgupta, 2017 for discussion of various causal narratives). Both causal accounts explain why there would be systematic group differences, and people may differ in which account they find more compelling. Indeed, prior work has documented substantial variation in the extent to which children, adolescents, and adults endorse structural versus intrinsic causes of inequality (Bañales et al., 2020; Diemer et al., 2019; Flanagan et al., 2014; Godfrey et al., 2019; Kluegel, 1990; Mistry et al., 2016; Rizzo et al., 2021).

\section{Structural Causes as a Unique Type of Extrinsic Cause}

On its face, structural causes may seem synonymous with extrinsic causes - that is, any causes that are external to the individual. However, structural causes are a distinct type of extrinsic cause: they are stable, interconnected institutional practices and cultural beliefs that consistently advantage some groups and disadvantage others (Bonilla-Silva, 2015; Haslanger, 2016; Jones, 1997; Rucker \& Richeson, 2021; Vasilyeva et al., 2018; Vasilyeva \& Lombrozo, 
2020). For example, the United States' GI Bill is a structural cause of racial wealth inequality because it was an institutional policy implemented in a way that consistently advantaged White Americans' ability to build wealth while disadvantaging Black Americans (Perea, 2015). In contrast, random adverse events, such as some natural disasters, are not structural causes but rather are merely extrinsic causes that are more evenly distributed across the population (see also "fatalistic causes"; Mistry et al., 2012, 2016).

The distinction between structural and merely extrinsic causes is nontrivial, as they constitute distinct patterns of reasoning (Hunt, 2002; Mistry et al., 2012; Weiss-Gal et al., 2009; Vasilyeva et al., 2021; Zucker \& Weiner, 1993). For example, Vasilyeva et al. (2021) found empirical evidence that inferring structural, but not merely extrinsic causes, heightens the salience of social categories (e.g., gender) and leads reasoners to expect that inequality will persist over time. These causes also point to qualitatively different policy responses. Addressing a merely extrinsic cause of poverty in a neighborhood (e.g., an unexpected hurricane) would warrant a local intervention effort. In contrast, a structural cause, like discriminatory housing policies, indicates that deeper institutional changes are needed. Given that structural causes have distinct properties and downstream consequences for reasoning and intervention, we propose that a framework for describing structural causal attribution is needed.

\section{Science of Inequality}

Before we discuss structural causal attribution, we note that the science on the actual causes of inequality suggests that social group disparities are due to a complex interplay of structural and intrinsic factors. For example, structural constraints, such as fewer educational opportunities for lower-income children, can negatively impact their intrinsic motivation to succeed (Browman et al., 2019; Laurin et al., 2019), suggesting that structural barriers can affect 
individual-level barriers to success (see also Lewis, 2016). At the same time, early and relatively minimal group differences may promote structural responses that reinforce and strengthen group distinctions (see, e.g., Wood \& Eagly, 2002).

Despite this complexity, we discuss structural causes as independent from intrinsic causes for two reasons. First, this simpler conceptualization maps onto previous empirical work on people's causal beliefs about inequality, which has focused on their endorsement of structural versus intrinsic causes (Diemer et al., 2019; Rizzo et al., 2018; Vasilyeva et al., 2018; Vasilyeva \& Lombrozo, 2020). Second, structural factors are typically less salient to people than intrinsic factors (Cimpian \& Salomon, 2014; Rhodes \& Mandalaywala, 2017), which motivates our focused analysis on how people successfully overcome barriers to structural thinking. That said, since our theoretical approach broadly applies to how people make causal inferences about inequality, it is also relevant for understanding intrinsic inferences.

\section{A Difference-Making Theoretical Framework of Structural Causal Attribution}

How do people successfully attribute inequality to structural causes? Across the psychology and education literature, the standard view is that people need to be made aware and accept that structural constraints exist (Cimpian \& Salomon, 2014; Piff et al., 2020; Rucker \& Richeson, 2021; Weisgram \& Bigler, 2007). From an educational perspective, this standard approach would seek to increase people's awareness of the structural constraints that certain social groups face (e.g., Nelson et al., 2013), and also seek to reduce psychological threat that may prevent people from accepting this information (e.g., Adams et al., 2006).

We propose that the standard approach addresses a critical part of the structural inference problem, but does not address it entirely. Although people need to be aware of structural constraints in order to consider them as potential causes of inequality (especially historical 
policies that have blatantly discriminated against certain groups; see Bonam et al., 2019; Nelson et al., 2013), this awareness does not always lead to causal attribution. In judging any outcome, people can consider a number of candidate variables, but identify some or even just one of the variables as the actual cause (Dweck \& Leggett, 1988; Gilbert \& Malone, 1995; Weiner, 1985). Consider this example from another domain: A student is trying to figure out why they failed a test. The student may be aware of many possible causes - their lack of preparation, poor skills, and an unfair test—but ultimately settle on their lack of preparation as being the actual cause.

Applying this logic to inequality, people could be made aware of and consider structural factors, but still privilege intrinsic factors as the cause of inequality (see Amemiya et al., 2021; Yang et al., 2021). Our framework seeks to address the second, critical part of structural inference: Once aware of structural constraints, what leads people to recognize them as causal? We propose that people must perceive that structural factors made a difference for inequality, above and beyond any intrinsic causes. We next describe the theoretical foundation for our framework: counterfactual theories of causal judgment.

Counterfactual theories of causal judgment. Counterfactual theories propose that people make causal judgments - i.e., $c$ caused $e$ - by comparing the known outcome, $e$, to a relevant alternative situation in which $c$ had not occurred (Gerstenberg et al., 2021; Lewis, 1973; Mackie, 1974; Woodward, 2005). If the comparison reveals that the target variable is “difference-making", such that the actual and counterfactual outcomes are different, people tend to endorse the variable as causal. ${ }^{1}$ In order to generate the counterfactual outcome, people

\footnotetext{
${ }^{1}$ We note that there are additional approaches to causal judgment, such as process theories (Dowe, 2000; Shultz, 1982) and associative theories (Kruschke \& Blair, 2000; Wasserman \& Berglan, 1998), which emphasize features of actual events when making causal judgments. According to a process view, people consider the causal mechanism linking a candidate cause to the outcome (e.g., whether a physical quantity like momentum transferred from Ball A to Ball B). Associative theories posit that reasoners infer causality based on the strength of the association between two events (e.g., whether Ball A is present whenever Ball B passes through the gate). Despite their success in describing some aspects of causal cognition, these accounts do not capture the complexity of our intuitions that some causes "matter" while others do not (e.g., the chalk that is transferred from the cue stick to Ball A is not relevant for the ball's movement).
} 
intervene on the target variable, either through direct or simulated manipulation (Gerstenberg et al., 2021; Halpern \& Hitchcock, 2015; Woodward, 2005). In our example above, the student may choose to study more for the next test to observe whether studying makes a difference for their performance. They may also rely on their prior knowledge that studying typically leads to better performance, and simulate the counterfactual that studying would have improved this particular test score (see Gerstenberg et al., 2021 for more on simulating counterfactuals).

There is robust evidence that people reason counterfactually to facilitate causal judgments about a range of domains including physical phenomena (e.g.,Gerstenberg et al., 2017; Goddu \& Gopnik, 2020; Sobel et al., 2004), common life events (e.g., Epstude \& Roese, 2008), and critically, societal issues (e.g., Lagnado \& Gerstenberg, 2017; Nolan, 2013; Sunstein, 2016; Wendell, 2020). For example, Sunstein (2016) notes that counterfactual claims are central to how people assess culpability in the law: When judges and juries assess whether someone was liable for an outcome (e.g., a car accident), they reason counterfactually about whether the outcome would still have occurred if the individual had acted differently (e.g., paid more attention to the road; see also Branscombe et al., 1996). Similarly, people use counterfactuals to make judgments about whether certain events or individuals had a causal impact on the course of history (Nolan, 2013; Sunstein, 2016; Wendell, 2020). In one illustrative study, adolescents were asked to reason about Adolf Hitler's importance for the Nazis' rise to power in Germany (Wendell, 2020). Notably, 82\% of participants spontaneously generated at least one counterfactual statement when addressing this question, with some participants inferring that Hitler was indeed difference-making (e.g., 'If it hadn't been for Hitler, the Nazis wouldn't have seized power"), while others rejected Hitler's importance because they believed that the outcome 
would have happened anyway (e.g., "Someone else could have taken his role before Hitler formed history in the way he did").

Application to structural causal attribution. Our framework contends that, similar to other domains of reasoning, people reason counterfactually to assess the causal role of structural factors on inequality (see Figure 1 for an overview of the framework). Here, the counterfactual question is: If the societal structure were different, would the level of inequality change? If people believe that removing societal constraints on disadvantaged groups would reduce inequality, they will recognize structural factors as causal. Consider the counterfactual comparison that journalist Isabel Wilkerson presents in her book, Caste: The Origins of Our Discontent, to argue for structural causes of racial inequality in life outcomes: “...on those cotton fields were opera singers, jazz musicians, playwrights, novelists, surgeons, attorneys, accountants, professors, journalists... We know that because that is what they and their children and now their grandchildren and even great-grandchildren have often chosen to become once they had the chance to choose for themselves..." (Wilkerson, 2020, emphasis added). Wilkerson's argument rests on the counterfactual that Black Americans would have made significantly different life choices had they been granted greater societal opportunities.

Critically, however, people can be aware of structural factors but ultimately reason that they are not difference-making and that intrinsic factors are the main cause of inequality. For this to be the case, the counterfactual outcome should reveal that inequality does not change when the disadvantaged group is given greater opportunities. Ex-Google employee, James Damore, used such counterfactual evidence in his 2017 anti-diversity memo, entitled, "Google's Ideological Echo Chamber." He acknowledges sexism against women, but emphasizes that gender inequalities remain large across many societies, and even become greater in egalitarian societies 
where women presumably have greater opportunities (see Vishkin, 2022, for a more nuanced interpretation of this phenomenon). Counterfactual reasoning is central to Damore's causal reasoning, but he reaches an intrinsic account because his counterfactual comparison suggests that gender inequalities persist regardless of structural factors.

As demonstrated in these examples, perceptions of difference-making appear to be central to people's structural attributions. Given that intervening on the target variable is a key part of this process (Gerstenberg et al., 2021; Halpern \& Hitchcock, 2015; Woodward, 2005), it is important to specify how people "intervene" on structural factors, which are, by definition, complex and multifaceted. We posit that reasoners consider changes to parts of the social system (i.e., "soft interventions"; Eronen, 2020), and generalize these inferences to the broader societal structure. Indeed, people regularly build rich causal models of the world from the relatively sparse data that is available to them (Gopnik et al., 2004). In the next sections, we identify two types of evidence that serve as soft interventions on societal structures (we refer to this throughout the paper as "interventional evidence"; see Griffiths et al., 2008). We posit that this evidence may be most efficiently obtained in the context of formal education (e.g., social studies), but we also describe how people may encounter relevant instances in everyday life.

Evidence type 1: Within-group change. The first type of interventional evidence, within-group change, is the most conceptually straightforward, and was captured in Wilkerson's (2020) comparison of Black Americans' life outcomes. Specifically, if people observe the removal of a structural constraint (i.e., a soft intervention), followed by improvements in a disadvantaged group's outcomes that narrow inequality between groups, they should infer that the constraint was difference-making. This counterfactual information reveals that the inequality is mutable and, critically, varies as a function of structural factors (see also Gopnik et al., 2017; 
Heyman, 2009; Kelley, 1973). Within-group change also directly refutes essentialist explanations by showing that social groups' properties are not fixed, but responsive to the environment (Bastian \& Haslam, 2006; Dar-Nimrod \& Heine, 2011; Donovan et al., 2019).

The importance of learning about within-group change to infer structural causes aligns with a theoretical proposal from Hetey and Eberhardt (2018). The authors propose that Americans may accept structural causes of racial inequalities in the criminal justice system if they are informed that crime in Black communities decreases when "tough-on-crime" policies are reformed or abandoned (e.g., easing minimum sentencing laws). This idea is an example of within-group change (i.e., decreases in crime rates) in response to removal of the group's structural constraints (i.e., fairer laws and policing practices). Notably, children and adults spontaneously make the reverse prediction: When they construe group differences as being caused by societal factors, they expect to see within-group change across social environments (Noyes \& Keil, 2020; Vasilyeva et al., 2018; Vasilyeva \& Lombrozo, 2020).

Although people cannot directly observe within-group change on a large scale, they may observe changes in their own or others' outcomes to make inferences about groups. For example, a racially marginalized student may notice improvements in their own academic performance when they transition to a more supportive educational context (see also Gopnik et al., 2017; Seiver et al., 2013 for how people use this type of evidence when making causal judgments about individuals). In one study of Black college students attending Historically Black Colleges and Universities, a student made precisely this counterfactual inference, "The social aspect is completely different at Black colleges, which I'm very thankful for. I probably wouldn't have the grades I have [elsewhere]" (Palmer et al., 2010). People may use these individual observations to simulate the counterfactual outcome at the group level, for example, inferring that Black 
Americans, as a group, are also likely to improve in their academic outcomes when provided with greater educational opportunities (see also Kubin et al., 2021; Piff et al., 2020 for the importance of personal experience when reasoning about societal issues).

Evidence type 2: Between-group comparison. Given that it may be challenging to observe the same group under different societal conditions (see Contextual Barriers section), people may turn to other evidence that informs the disadvantaged group's counterfactual outcome. We identify a second type of evidence, between-group comparison, which relies on the advantaged group who experiences fewer structural constraints as the counterfactual. The advantaged group offers insight into what may have happened for the disadvantaged group had they experienced the same favorable societal circumstances. To illustrate, when explaining women's underrepresentation in STEM, people may consider the career outcomes of men, who typically have greater societal support to participate in STEM. People may then reason that women's representation may look more like men's had women been given the same support. Notably, this logic is embedded in the standard educational approach to structural inference, which informs students about the different societal constraints that groups experience.

At least for novel inequalities, there is evidence that the standard approach of using between-group comparisons promotes structural attributions (Brown \& Bigler, 2004; Rizzo et al., 2018; Vasilyeva et al., 2018; Vasilyeva \& Lombrozo, 2020). In one illustrative study by Vasilyeva et al. (2018), children and adults were introduced to an unfamiliar inequality in which girls play the game "Green-Ball" much less frequently than boys. Participants were then presented with a between-group comparison in constraints: Girls' classrooms, but not boys' classrooms, had physical barriers to playing Green-Ball (i.e., girls' classrooms had a rule in which they had to throw a pebble into a small bucket to play, whereas boys' classrooms had a 
larger bucket). This evidence led participants to explain the inequality in terms of girls' structural barriers to playing the game. Our framework posits that participants' structural attributions were supported by the fact that boys' outcomes (i.e., they played Green-Ball at higher rates) illustrated what would have happened if girls' environments afforded them opportunities to play Green-Ball.

To promote structural thinking about well-known inequalities, however, the standard between-group comparison approach needs to meet additional assumptions. Specifically, reasoners must perceive that the two groups are matched at baseline on all relevant intrinsic characteristics (e.g., abilities, motivation), such that the only meaningful difference between the groups is their societal constraints (for related theorizing see Hatzenbuehler, 2016; Lantz et al., 2021; Lu et al., 2020). This assumption is easily met for novel inequalities that reasoners have no prior beliefs about (e.g., gender differences in playing "Green-Ball”), but not for inequalities that are widely stereotyped as being intrinsically based (e.g., gender differences in playing with dolls and trucks). If reasoners believe the compared groups are intrinsically different, they may reason that structural constraints are only correlated with intrinsic differences and are not causal for inequality (see Amemiya et al., 2021). Compelling between-group comparisons thus rely on the compared groups being carefully matched at baseline (e.g., men and women with similar baseline interest and ability in STEM).

Can reasoners make compelling between-group comparisons in their everyday lives? We propose that it is possible to the extent that reasoners can compare individuals from different social groups with similar traits. Socially diverse contexts that allow contact with many individuals from different social groups may afford such comparisons. For example, students in racially diverse schools may notice that Black and White students who engage in the same 
behaviors are treated differently by teachers (Yeager et al., 2017). As one Black adolescent observed, "I felt [my teacher] was being really racist to me because there was some White girl talking, and then I started talking, and then the teacher yelled at me" (Hope et al., 2015). After making these observations about individuals, reasoners may infer that groups also experience differential treatment that leads to inequality above and beyond any intrinsic differences.

\section{Barriers to Structural Causal Evidence}

Our framework has proposed two types of interventional evidence that can reliably promote structural thinking: within-group change and well-matched between-group comparisons. However, a theoretical framework should also account for why structural thinking is so rare (Cimpian \& Salomon, 2014; Dunlea \& Heiphetz, 2020; Hunt, 2007; Kluegel \& Smith, 1986; Mistry et al., 2012). We contend that there are barriers to the availability and acceptance of both types of evidence. We consider contextual, cognitive, and motivational barriers in turn.

Contextual barriers. Social contexts generally limit people's ability to observe withingroup change and between-group comparisons, both in everyday life and across history. A major limitation to observing within-group change, which entails observing groups' responses to societal changes, is that societal structures tend to be stable, rather than variable. Indeed, the societal institutions and cultural beliefs that contribute to inequality often persist across generations and settings (Bonilla-Silva, 2015; Haslanger, 2016; Hetey \& Eberhardt, 2018). Two particularly salient examples are racial biases toward people of African descent and gendered societal roles for males and females. Moreover, largescale societal changes that $d o$ occur and the subsequent changes in inequality (e.g., America's Great Migration; Wilkerson, 2010) may be forgotten over the course of history. 
With respect to making compelling between-group comparisons, people must be in social contexts that are diverse enough to compare individuals who are from different social groups but have similar traits. The majority of people lack exposure to diverse social environments, particularly within the United States. Demography studies reveal high rates of segregation between social groups: For example, high-income American families tend to have low exposure to families from other socioeconomic backgrounds (Bischoff \& Reardon, 2014; Reardon et al., 2018), and White American families often live in neighborhoods with other White individuals (Grigoryeva \& Ruef, 2015). This issue may also come into play for gender: Even though most people have exposure to individuals of the opposite gender at home or at school, they may have few close relationships with differently-gender peers that would allow for insight into the other group's experiences (Maccoby \& Jacklin, 1987; Mehta \& Wilson, 2020).

Cognitive barriers. Our framework also suggests that there are cognitive barriers that can lead people to reject structural causal evidence, even when this information becomes available. As described in previous work, structural systems are complex and abstract, which may make structural information difficult to process (Cimpian \& Salomon, 2014; Yang et al., 2021). This complexity may also explain why young children, who have relatively less knowledge about structural factors and limited cognitive resources to reason about such information, are especially unlikely to consider societal influences (Cimpian \& Steinberg, 2014).

Critically, however, certain prior beliefs can impede structural inferences, even when the relevant evidence is presented in a way that is simple and accessible. In particular, pre-existing essentialist beliefs may lead people to reject both types of interventional evidence that we have identified. As noted earlier, if people believe that groups are intrinsically different, then betweengroup comparisons of structural constraints are confounded by these baseline differences. Thus, 
someone with strong essentialist beliefs might reject a comparison between different groups' societal opportunities because they assume that one group cannot be used to make counterfactual judgments about the other. Moreover, even if the groups were matched on important potential confounds like interest and ability, essentialist beliefs may lead people to assume that deep, unobservable differences still exist between the groups, thus compromising any further comparison in their constraints.

Relative to between-group comparisons, essentialist beliefs may pose less of a challenge to evidence of within-group change, given that within-group change directly refutes essentialist ideas that groups' properties are fixed over time (Dar-Nimrod \& Heine, 2011; Gelman, 2003). However, it is also possible that people with especially strong essentialist beliefs can accommodate within-group change in an essentialist framework. For example, people may assume that within-group change is also driven by intrinsic processes, such as groups' genes “evolving” differently (see Shtulman \& Schulz, 2008 for related misunderstanding).

Motivational barriers. Motivated reasoning has been proposed as a key barrier to people's structural reasoning (Phillips \& Lowery, 2018; Piff et al., 2020; Rucker \& Richeson, 2021). Social psychological perspectives have highlighted people's persistent denial of structural causes, even after the causal link between structural factors and inequality is made obvious. This persistent denial is believed to stem from the psychological threat of structural explanations: They challenge many people's preferred belief that societal systems are fair and call into question the assumption that life successes are rooted in merit alone (Jost, 2019; Kraus, Onyeador, et al., 2019; Phillips \& Lowery, 2018, 2020). This threat is likely to be greatest for members of advantaged groups whose positions in society are justified by intrinsic explanations (Cech \& Blair-Loy, 2010; Cozzarelli et al., 2001; Hartmann et al., 2009; Nelson et al., 2013; 
Panofsky et al., 2021; Phillips \& Lowery, 2020) and to people with a social dominance orientation (i.e., a preference for social hierarchies; Pratto et al., 1994). Here, however, we take a step back in the inferential process to consider how motivations may affect whether people infer the causal link between structural factors and inequality in the first place. Our framework, which seeks to complement existing social psychological frameworks, proposes at least three mechanisms by which motivated reasoning affects the initial causal inference.

First, the type of counterfactual thinking needed to evaluate structural causes requires cognitive effort, in which people must represent actual inequality and then compare it to a counterfactual situation to determine if inequality would have been different (Byrne, 2016). Individuals who are satisfied with the status quo (e.g., members of advantaged groups) may be unmotivated to engage in this reasoning process. Indeed, people are less likely to ask counterfactual "what if" questions when they are satisfied with an outcome (Roese \& Epstude, 2017), and they are less likely to search for causal explanations for outcomes that are familiar and pose no threat (e.g., Gendolla \& Koller, 2001). Thus, some people may never seriously evaluate the causes of inequality, especially structural causes.

Second, even if people $d o$ engage in counterfactual reasoning to evaluate structural causes, they may strategically select or misrepresent counterfactual outcomes that support the conclusions they wish to make (see also Markman et al., 2008). As one relevant example, when asked to assess the United States' progress toward racial equality, White Americans often used the past as the counterfactual reference point, which emphasizes the country's progress, while racially minoritized people referenced ideal standards, which emphasizes the progress that has yet to be made (Eibach \& Ehrlinger, 2006). Relatedly, recent work finds that White Americans resist accepting information indicating that this comparison is false (i.e., that the United States 
has actually not made much progress toward racial equality from the past to the present; Onyeador et al., 2021).

A third mechanism is that people may strategically avoid certain situations that could influence the kinds of counterfactual comparisons they can make (see also Byrne, 2016; Hitchcock, 2011; Kahneman \& Miller, 1986 for the variety of factors that influence the availability of counterfactuals). For example, people who are motivated to perceive the world as fair may avoid social contexts that could challenge this view (e.g., interacting with individuals outside of their racial group). Segregation from other groups may consequently limit the evidence available to make between-group comparisons of societal constraints (Merolla et al., 2011; Mijs, 2018). Overall, we propose that future work integrating social and cognitive psychological approaches could help inform how motivated reasoning impedes each part of the structural attribution process.

\section{Additional Directions for Future Research}

In addition to providing a cognitive theoretical framework for understanding structural thinking, our approach raises new questions for empirical research. We have discussed structural causes as a broad category, but an open question is whether some types of structural causes are more salient to people. We posit that people will be more accepting of structural causes that are concrete and deterministic, such as former policies at universities that completely forbade people of color and women from certain areas of study, compared to abstract and probabilistic structural causes, such as unwelcoming work environments where underrepresented groups are negatively stereotyped (Bian et al., 2018; Master et al., 2016). The more abstract and probabilistic the constraint, the more it is possible for people to reason that the disadvantaged group could have acted differently if they wanted to (e.g., the group could have persisted in 
STEM despite a hostile work environment), thus reducing its perceived causal power (see Walker et al., 2015).

Further, one general challenge for counterfactual accounts is to specify the alternatives that people spontaneously consider (Hesslow, 1988). In some domains, people tend to consider the same counterfactuals (e.g., physical causation; Gerstenberg et al., 2017; see also Byrne, 2016). When reasoning about inequality, however, people may consider a much wider range of counterfactuals that serve various motivational and epistemic goals (Eibach \& Ehrlinger, 2006; Kohler-Hausmann \& Dembroff, 2022). For example, if people are interested in the effect of a specific policy, they may consider what happens to a disadvantaged group within the same societal context over time (e.g., changes in outcomes for American women under different social policies). But, if people are interested in the causal role of entire societal structures, they may care more about the group's outcomes across different societal contexts (e.g., comparing the outcomes for women living in different countries).

While we have largely focused on instances of within-group change for members of particular social groups (e.g., the changing life outcomes of "Black Americans"), it is also possible that learning how group categories themselves have changed over time would bolster structural thinking (e.g., the evolving conceptualizations of race and gender throughout history, see Dembroff, 2018; Spencer, 2019). Recognizing that social group categories are shaped by cultural conventions denaturalizes them, and in turn may reduce the essentialist beliefs that impede structural thinking. In support of this idea, a recent anti-essentialist educational intervention that incorporated information about the changing nature of racial categories reduced people's racial essentialism (Donovan et al., 2019). 
There are also important questions regarding between-group comparisons. Here, we have focused on comparisons that hold intrinsic factors constant (e.g., interest and ability) to determine if structural factors are difference-making. However, people might also hold structural constraints constant to determine if groups' intrinsic properties are difference-making. Specifically, if groups have unequal outcomes despite similar structural constraints, people may assume that the inequality is caused by characteristics inherent to the group (Vasilyeva et al., 2018; Vasilyeva \& Lombrozo, 2020; Yang et al., 2021). Of course, this raises questions about whether two groups' structural constraints are truly comparable. For example, scholars have argued that comparing Black Americans to other racial minority groups who also experience racial discrimination (e.g., Asian Americans), are unfair comparisons because Black Americans' societal oppression is qualitatively different (Godfrey et al., 2019; Lewis, 2016). However, we speculate that lay individuals may make such comparisons when they are available, even if they are invalid, when evaluating the causes of inequality.

Our framework may also inform current theorizing about belief polarization. Given the widespread segregation between social groups, it is likely that groups systematically differ in the evidence they observe, which may lead them to privilege different causes of inequality. Supporting this idea, a study by Jefferson and colleagues (2021) found that Black and White Americans made different inferences about the most likely cause for a police shooting of a Black civilian: Black Americans more strongly inferred structural causes (i.e., police racial bias) and White Americans more strongly inferred individual causes (e.g., the civilian may have attacked the officer). In line with our account, the authors proposed that this pattern may be due, in part, to differences in each group's exposure to racial bias in policing. 
Finally, we note two important limitations that reflect broader limitations of the current psychological literature. First, we have drawn primarily from studies conducted in the United States (Cheon et al., 2020; Henrich et al., 2010), where one group (i.e., White Americans) possesses structural advantages in almost all aspects of society (e.g., economically, politically, numerically; Roberts \& Rizzo, 2020). One interesting line of research would be to examine how people reason about inequality in societal contexts where structural advantages vary across groups. For example, in Indonesia, Native Indonesians are a numerical majority and are wellrepresented in the government, but have significantly less wealth than Chinese Indonesians (Brown et al., 2018). There may be even greater disagreement about structural attributions in such contexts where societal forces are impacting groups in different directions.

Second, while we have focused on inequalities between individual social groups (e.g., two racial groups), research on people's understanding of intersecting forms of societal oppression is critical (e.g., the unique forms of oppression that Black women experience; Cole, 2009; Crenshaw, 1989; Lei \& Rhodes, 2021; Purdie-Vaughns \& Eibach, 2008). An intersectional understanding requires more complex reasoning about inequality: Reasoners must be aware of the societal constraints that subgroups of people experience, and need to keep at least four groups in mind rather than just two (e.g., Black women, Black men, White women, and White men). Although more complicated, even young children and adolescents have intersectional stereotypes for various subgroups (Ghavami \& Peplau, 2018; Jaxon et al., 2019; Lei et al., 2020), suggesting that people could also learn about intersectional forms of inequality.

\section{Conclusion}

There is strong interest in people's structural thinking about inequality, as it can be used to improve their understanding of human difference and their ability to make informed 
judgments about societal policies (Donovan et al., 2019; McLoyd, 2019; Mijs, 2018; Mistry et al., 2012; Phillips \& Lowery, 2018; Piff et al., 2020; Rucker \& Richeson, 2021). Moving forward, however, we note an important caveat to consider: While inferring structural causes can reduce prejudice against disadvantaged groups, this is not always the case. Our argument is about inequality being reduced when structural constraints are removed. Yet some people may argue that inequality is reduced only when structural constraints are added, which could increase prejudice against minoritized groups. For example, believing that affirmative action policies discriminate against majority groups and is the only reason for increased representation of minoritized groups is a structural inference (Norton \& Sommers, 2011), but one that reinforces negative ability stereotypes (Leslie et al., 2014). Thus, much like essentialist reasoning (see Peretz-Lange, 2021), structural thinking can both reduce and increase negative attitudes toward disadvantaged groups depending on the phenomenon being evaluated.

Here, we have focused on people's structural thinking about inequality, and have proposed a cognitive framework that identifies the specific evidence to support structural causal attributions, as well as the contextual, cognitive, and motivational barriers to this inferential process. This framework may help to offer a path to more accurate lay understanding of persistent social inequalities. 


\section{References}

Adams, G., Tormala, T. T., \& O’Brien, L. T. (2006). The effect of self-affirmation on perception of racism. Journal of Experimental Social Psychology, 42(5), 616-626. https://doi.org/10.1016/j.jesp.2005.11.001

Amemiya, J., Mortenson, E., Ahn, S., Walker, C. M., \& Heyman, G. D. (2021). Children acknowledge physical constraints less when actors behave stereotypically: Gender stereotypes as a case study. Child Development. https://doi.org/10.1111/cdev.13643

Bañales, J., Marchand, A. D., Skinner, O. D., Anyiwo, N., Rowley, S. J., \& Kurtz-Costes, B. (2020). Black adolescents' critical reflection development: Parents' racial socialization and attributions about race achievement gaps. Journal of Research on Adolescence, 30(S2), 403-417. https://doi.org/10.1111/jora.12485

Bastian, B., \& Haslam, N. (2006). Psychological essentialism and stereotype endorsement. Journal of Experimental Social Psychology, 42(2), 228-235. https://doi.org/10.1016/j.jesp.2005.03.003

Bian, L., Leslie, S. J., \& Cimpian, A. (2018). Evidence of bias against girls and women in contexts that emphasize intellectual ability. American Psychologist, 73(9), 1139-1153. https://doi.org/10.1037/amp0000427

Bischoff, K., \& Reardon, S. F. (2014). Residential segregation by income, 1970-2009. Diversity and Disparities: America Enters A New Century, 208-234.

Bonam, C. M., Nair Das, V., Coleman, B. R., \& Salter, P. (2019). Ignoring history, denying racism: Mounting evidence for the Marley Hypothesis and epistemologies of ignorance. Social Psychological and Personality Science, 10(2), 257-265. https://doi.org/10.1177/1948550617751583 
Bonilla-Silva, E. (2015). The structure of racism in color-blind, "post-racial" America. American Behavioral Scientist, 59(11), 1358-1376. https://doi.org/10.1177/0002764215586826

Branscombe, N. R., Owen, S., Garstka, T. A., \& Coleman, J. (1996). Rape and accident counterfactuals: Who might have done otherwise and would it have changed the outcome? Journal of Applied Social Psychology, 26(12), 1042-1067. https://doi.org/10.1111/j.1559-1816.1996.tb01124.x

Browman, A. S., Destin, M., Kearney, M. S., \& Levine, P. B. (2019). How economic inequality shapes mobility expectations and behaviour in disadvantaged youth. Nature Human Behaviour, 3(3), 214-220. https://doi.org/10.1038/s41562-018-0523-0

Brown, C. S., \& Bigler, R. S. (2004). Children's perceptions of gender discrimination. Developmental Psychology, 40(5), 714-726. https://doi.org/10.1037/0012-1649.40.5.714

Brown, C. S., Tam, M., \& Aboud, F. (2018). Ethnic prejudice in young children in Indonesia: Intervention attempts using multicultural friendship stories. International Journal of Early Childhood, 50(1), 67-84. https://doi.org/10.1007/s13158-018-0214-z

Byrne, R. M. J. (2016). Counterfactual thought. Annual Review of Psychology, 67(1), 135-157. https://doi.org/10.1146/annurev-psych-122414-033249

Carmichael, S., \& Hamilton, C. V. (1967). Black power: The politics of liberation in America. Vintage Books.

Cech, E. A., \& Blair-Loy, M. (2010). Perceiving glass ceilings? Meritocratic versus structural explanations of gender inequality among women in science and technology. Social Problems, 57(3), 371-397. https://doi.org/10.1525/sp.2010.57.3.371

Cheon, B. K., Melani, I., \& Hong, Y. (2020). How USA-centric is psychology? An archival study of implicit assumptions of generalizability of findings to human nature based on 
origins of study samples. Social Psychological and Personality Science, 11(7), 928-937. https://doi.org/10.1177/1948550620927269

Cheryan, S., Ziegler, S. A., Montoya, A. K., \& Jiang, L. (2017). Why are some STEM fields more gender balanced than others? Psychological Bulletin, 143(1), 1-35. https://doi.org/10.1037/bu10000052

Cimpian, A., \& Salomon, E. (2014). The inherence heuristic: An intuitive means of making sense of the world, and a potential precursor to psychological essentialism. Behavioral and Brain Sciences, 37(5), 461-480. https://doi.org/10.1017/S0140525X13002197

Cimpian, A., \& Steinberg, O. D. (2014). The inherence heuristic across development: Systematic differences between children's and adults' explanations for everyday facts. Cognitive Psychology, 75, 130-154. https://doi.org/10.1016/j.cogpsych.2014.09.001

Cole, E. R. (2009). Intersectionality and research in psychology. American Psychologist, 64(3), 170-180. https://doi.org/10.1037/a0014564

Cooley, E., Hester, N., Cipolli, W., Rivera, L. I., Abrams, K., Pagan, J., Sommers, S. R., \& Payne, K. (2020). Racial biases in officers' decisions to frisk are amplified for Black people stopped among groups leading to similar biases in searches, arrests, and use of force. Social Psychological and Personality Science, 11(6), 761-769. https://doi.org/10.1177/1948550619876638

Cozzarelli, C., Wilkinson, A. V., \& Tagler, M. J. (2001). Attitudes toward the poor and attributions for poverty. Journal of Social Issues, 57(2), 207-227. https://doi.org/10.1111/0022-4537.00209 
Crenshaw, K. (1989). Demarginalizing the intersection of race and sex: A black feminist critique of antidiscrimination doctrine, feminist theory and antiracist politics. University of Chicago Legal Forum, 139-167.

Dar-Nimrod, I., \& Heine, S. J. (2011). Genetic essentialism: On the deceptive determinism of DNA. Psychological Bulletin, 137(5), 800-818. https://doi.org/10.1037/a0021860

Dembroff, R. (2018). Real talk on the metaphysics of gender. Philosophical Topics, 46(2), 2150. https://doi.org/10.5840/philtopics201846212

Dennehy, T. C., \& Dasgupta, N. (2017). Female peer mentors early in college increase women's positive academic experiences and retention in engineering. Proceedings of the National Academy of Sciences, 114(23), 5964-5969. https://doi.org/10.1073/pnas.1613117114

Diemer, M. A., Voight, A. M., Marchand, A. D., \& Bañales, J. (2019). Political identification, political ideology, and critical social analysis of inequality among marginalized youth. Developmental Psychology, 55(3), 538-549. https://doi.org/10.1037/dev0000559

Donovan, B. M. (2016). Framing the genetics curriculum for social justice: An experimental exploration of how the biology curriculum influences beliefs about racial difference. Science Education, 100(3), 586-616. https://doi.org/10.1002/sce.21221

Donovan, B. M., Semmens, R., Keck, P., Brimhall, E., Busch, K. C., Weindling, M., Duncan, A., Stuhlsatz, M., Bracey, Z. B., Bloom, M., Kowalski, S., \& Salazar, B. (2019). Toward a more humane genetics education: Learning about the social and quantitative complexities of human genetic variation research could reduce racial bias in adolescent and adult populations. Science Education, 103(3), 529-560. https://doi.org/10.1002/sce.21506 
Dore, R. A., Hoffman, K. M., Lillard, A. S., \& Trawalter, S. (2018). Developing cognitions about race: White 5- to 10-year-olds' perceptions of hardship and pain. European Journal of Social Psychology, 48(2), O121-O132. https://doi.org/10.1002/ejsp.2323

Dowe, P. (2000). Physical causation. Cambridge University Press.

Duncan, G. J., Magnuson, K., \& Votruba-Drzal, E. (2017). Moving beyond correlations in assessing the consequences of poverty. Annual Review of Psychology, 68(1), 413-434. https://doi.org/10.1146/annurev-psych-010416-044224

Dunlea, J. P., \& Heiphetz, L. (2020). Children's and adults' understanding of punishment and the criminal justice system. Journal of Experimental Social Psychology, 87, 103913. https://doi.org/10.1016/j.jesp.2019.103913

Dweck, C. S., \& Leggett, E. L. (1988). A social-cognitive approach to motivation and personality. Psychological Review, 95(2), 256-273. https://doi.org/10.1037/0033295X.95.2.256

Eibach, R. P., \& Ehrlinger, J. (2006). “Keep your eyes on the prize”: Reference points and racial differences in assessing progress toward equality. Personality and Social Psychology Bulletin, 32(1), 66-77. https://doi.org/10.1177/0146167205279585

Elenbaas, L., \& Killen, M. (2016). Age-related changes in children's associations of economic resources and race. Frontiers in Psychology, 7(JUN), 1-9. https://doi.org/10.3389/fpsyg.2016.00884

Eronen, M. I. (2020). Causal discovery and the problem of psychological interventions. New Ideas in Psychology, 59, 100785. https://doi.org/10.1016/j.newideapsych.2020.100785

Flanagan, C. A., Kim, T., Pykett, A., Finlay, A., Gallay, E. E., \& Pancer, M. (2014). Adolescents' theories about economic inequality: Why are some people poor while others 
are rich? Developmental Psychology, 50(11), 2512-2525.

https://doi.org/10.1037/a0037934

Gelman, S. A. (2003). The essential child. Oxford University Press.

Gendolla, G. H. E., \& Koller, M. (2001). Surprise and motivation of causal search: How are they affected by outcome valence and importance? Motivation and Emotion, 25(4), 327-349. https://doi.org/10.1023/A:1014867700547

Gerstenberg, T., Goodman, N., Lagnado, D., \& Tenenbaum, J. B. (2021). A counterfactual simulation model of causal judgments for physical events. Psychological Review. https://doi.org/10.31234/osf.io/7zj94

Gerstenberg, T., Peterson, M. F., Goodman, N. D., Lagnado, D. A., \& Tenenbaum, J. B. (2017). Eye-tracking causality. Psychological Science, 28(12), 1731-1744. https://doi.org/10.1177/0956797617713053

Ghavami, N., \& Peplau, L. A. (2018). Urban middle school students'stereotypes at the intersection of sexual orientation, ethnicity, and gender. Child Development, 89(3), 881896. https://doi.org/10.1111/cdev.12763

Gilbert, D. T., \& Malone, P. S. (1995). The correspondence bias. Psychological Bulletin, 117(1), 21-38. https://doi.org/10.1037/0033-2909.117.1.21

Goddu, M. K., \& Gopnik, A. (2020). Learning what to change: Young children use "differencemaking" to identify causally relevant variables. Developmental Psychology, 56(2), 275284. https://doi.org/10.1037/dev0000872

Godfrey, E. B., Burson, E. L., Yanisch, T. M., Hughes, D., \& Way, N. (2019). A bitter pill to swallow? Patterns of critical consciousness and socioemotional and academic well-being 
in early adolescence. Developmental Psychology, 55(3), 525-537.

https://doi.org/10.1037/dev0000558

Gopnik, A., Glymour, C., Sobel, D. M., Schulz, L. E., Kushnir, T., \& Danks, D. (2004). A theory of causal learning in children: Causal maps and Bayes nets. Psychological Review, 111(1), 3-32. https://doi.org/10.1037/0033-295X.111.1.3

Gopnik, A., O’Grady, S., Lucas, C. G., Griffiths, T. L., Wente, A., Bridgers, S., Aboody, R., Fung, H., \& Dahl, R. E. (2017). Changes in cognitive flexibility and hypothesis search across human life history from childhood to adolescence to adulthood. Proceedings of the National Academy of Sciences, 114(30), 7892-7899.

https://doi.org/10.1073/pnas.1700811114

Griffiths, T. L., Kemp, C., \& Tenenbaum, J. B. (2008). Bayesian models of cognition. In Cambridge handbook of computational cognitive modeling (pp. 59-100). Cambridge University Press.

Grigoryeva, A., \& Ruef, M. (2015). The historical demography of racial segregation. American Sociological Review, 80(4), 814-842. https://doi.org/10.1177/0003122415589170

Halpern, J. Y., \& Hitchcock, C. (2015). Graded causation and defaults. The British Journal for the Philosophy of Science, 66(2), 413-457. https://doi.org/10.1093/bjps/axt050

Hartmann, D., Gerteis, J., \& Croll, P. R. (2009). An empirical assessment of Whiteness theory: Hidden from how many? Social Problems, 56(3), 403-424. https://doi.org/10.1525/sp.2009.56.3.403

Haslanger, S. (2016). What is a (social) structural explanation? Philosophical Studies, 173(1), 113-130. https://doi.org/10.1007/s11098-014-0434-5 
Hatzenbuehler, M. L. (2016). Structural stigma: Research evidence and implications for psychological science. American Psychologist, 71(8), 742-751. https://doi.org/10.1037/amp0000068

Hatzenbuehler, M. L., McLaughlin, K. A., Keyes, K. M., \& Hasin, D. S. (2010). The impact of institutional discrimination on psychiatric disorders in lesbian, gay, and bisexual populations: A prospective study. American Journal of Public Health, 100(3), 452-459. https://doi.org/10.2105/AJPH.2009.168815

Henrich, J., Heine, S. J., \& Norenzayan, A. (2010). The weirdest people in the world? Behavioral and Brain Sciences, 33(2-3), 61-83. https://doi.org/10.1017/S0140525X0999152X

Henry, D. A., Betancur Cortés, L., \& Votruba-Drzal, E. (2020). Black-White achievement gaps differ by family socioeconomic status from early childhood through early adolescence. Journal of Educational Psychology, 112(8), 1471-1489. https://doi.org/10.1037/edu0000439

Herd, P., Freese, J., Sicinski, K., Domingue, B. W., Mullan Harris, K., Wei, C., \& Hauser, R. M. (2019). Genes, gender inequality, and educational attainment. American Sociological Review, 84(6), 1069-1098. https://doi.org/10.1177/0003122419886550

Hesslow, G. (1988). The problem of causal selection. In Contemporary science and natural explanation: Commonsense conceptions of causality. New York University Press.

Hetey, R. C., \& Eberhardt, J. L. (2018). The numbers don't speak for themselves: Racial disparities and the persistence of inequality in the criminal justice system. Current Directions in Psychological Science, 27(3), 183-187. https://doi.org/10.1177/0963721418763931 
Heyman, G. D. (2009). Children's reasoning about traits. In P. Bauer (Ed.), Advances in Child Development and Behavior (pp. 105-143). Elsevier Inc. https://doi.org/10.1016/S00652407(09)03703-3

Hitchcock, C. (2011). Trumping and contrastive causation. Synthese, 181(2), 227-240. https://doi.org/10.1007/s11229-010-9799-y

Hoffman, K. M., Trawalter, S., Axt, J. R., \& Oliver, M. N. (2016). Racial bias in pain assessment and treatment recommendations, and false beliefs about biological differences between blacks and whites. Proceedings of the National Academy of Sciences of the United States of America, 113(16), 4296-4301. https://doi.org/10.1073/pnas.1516047113

Hope, E. C., Skoog, A. B., \& Jagers, R. J. (2015). 'It'll bever be the White kids, it'll always be us": Black high school students' evolving critical analysis of racial discrimination and inequity in schools. Journal of Adolescent Research, 30(1), 83-112. https://doi.org/10.1177/0743558414550688

Hunt, M. O. (2002). Religion, race/ethnicity, and beliefs about poverty. Social Science Quarterly, 83(3), 810-831. https://doi.org/10.1111/1540-6237.00116

Hunt, M. O. (2007). African American, Hispanic, and White beliefs about Black/White inequality, 1977-2004. American Sociological Review, 72(3), 390-415. https://doi.org/10.1177/000312240707200304

Jaxon, J., Lei, R. F., Shachnai, R., Chestnut, E. K., \& Cimpian, A. (2019). The acquisition of gender stereotypes about intellectual ability: Intersections with race. Journal of Social Issues, 75(4), 1192-1215. https://doi.org/10.1111/josi.12352 
Jefferson, H., Neuner, F. G., \& Pasek, J. (2021). Seeing blue in black and white: Race and perceptions of officer-involved shootings. Perspectives on Politics, 19(4), 1165-1183. https://doi.org/10.1017/S1537592720003618

Jones, J. M. (1997). Prejudice and racism (2nd ed.). McGraw-Hill.

Jost, J. T. (2019). A quarter century of system justification theory: Questions, answers, criticisms, and societal applications. British Journal of Social Psychology, 58(2), 263314. https://doi.org/10.1111/bjso.12297

Kahneman, D., \& Miller, D. T. (1986). Norm theory: Comparing reality to its alternatives. Psychological Review, 93(2), 136-153. https://doi.org/10.1037/0033-295X.93.2.136

Kelley, H. H. (1973). The processes of causal attribution. American Psychologist, 28(2), 107128. https://doi.org/10.1037/h0034225

Kluegel, J. R. (1990). Trends in Whites' explanations of the Black-White gap in socioeconomic status, 1977-1989. American Sociological Review, 55(4), 512. https://doi.org/10.2307/2095804

Kluegel, J. R., \& Smith, E. R. (1986). Beliefs about inequality: Americans'views of what is and what ought to be. Aldine De Gruyter.

Kohler-Hausmann, I., \& Dembroff, R. (2022). Supreme confusion about causality at the Supreme Court. CUNY Law Review, 25(1), 1-35.

Kraus, M. W., Onyeador, I. N., Daumeyer, N. M., Rucker, J. M., \& Richeson, J. A. (2019). The misperception of racial economic inequality. Perspectives on Psychological Science, 14(6), 899-921. https://doi.org/10.1177/1745691619863049

Kraus, M. W., Torrez, B., Park, J. W., \& Ghayebi, F. (2019). Evidence for the reproduction of social class in brief speech. Proceedings of the National Academy of Sciences of the 
United States of America, 116(46), 22998-23003.

https://doi.org/10.1073/pnas.1900500116

Kruschke, J. K., \& Blair, N. J. (2000). Blocking and backward blocking involve learned inattention. Psychonomic Bulletin \& Review, 7(4), 636-645. https://doi.org/10.3758/BF03213001

Kubin, E., Puryear, C., Schein, C., \& Gray, K. (2021). Personal experiences bridge moral and political divides better than facts. Proceedings of the National Academy of Sciences, 118(6), e2008389118. https://doi.org/10.1073/pnas.2008389118

Lagnado, D. A., \& Gerstenberg, T. (2017). Causation in legal and moral reasoning (M. R. Waldmann, Ed.; Vol. 1). Oxford University Press. https://doi.org/10.1093/oxfordhb/9780199399550.013.30

Lantz, B., Wenger, M. R., \& Craig, C. J. (2021). What if they were White? The differential arrest consequences of victim characteristics for Black and White co-offenders. Social Problems, spab043. https://doi.org/10.1093/socpro/spab043

Laurin, K., Engstrom, H. R., \& Alic, A. (2019). Motivational accounts of the vicious cycle of social status: An integrative framework using the United States as a case study. Perspectives on Psychological Science, 14(2), 107-137. https://doi.org/10.1177/1745691618788875

Lawrence, E., \& Mollborn, S. (2017). Racial/ethnic patterns of kindergarten school enrollment in the United States. Sociological Forum, 32(3), 635-658. https://doi.org/10.1111/socf.12352 
Lei, R. F., Leshin, R. A., \& Rhodes, M. (2020). The development of intersectional social prototypes. Psychological Science, 31(8), 911-926.

https://doi.org/10.1177/0956797620920360

Lei, R. F., \& Rhodes, M. (2021). Why developmental research on social categorization needs intersectionality. Child Development Perspectives, 15(3), 143-147. https://doi.org/10.1111/cdep.12421

Leslie, L. M., Mayer, D. M., \& Kravitz, D. A. (2014). The stigma of affirmative action: A stereotyping-based theory and meta-analytic test of the consequences for performance. Academy of Management Journal, 57(4), 964-989. https://doi.org/10.5465/amj.2011.0940

Leslie, S.-J., Cimpian, A., Meyer, M., \& Freeland, E. (2015). Expectations of brilliance underlie gender distributions across academic disciplines. Science, 347(6219), 262-265. https://doi.org/10.1126/science.1261375

Lewis, C. (2016). Inequality, incentives, criminality, and blame. Legal Theory, 22(2), 153-180. https://doi.org/10.1017/S1352325217000052

Lewis, D. (1973). Causation. The Journal of Philosophy, 70(17), 556-567. https://doi.org/10.2307/2025310

Liben, L. S., Bigler, R. S., \& Krogh, H. R. (2001). Pink and blue collar jobs: Children’s judgments of job status and job aspirations in relation to sex of worker. Journal of Experimental Child Psychology, 79(4), 346-363. https://doi.org/10.1006/jecp.2000.2611

Lu, J. G., Liu, X. L., Liao, H., \& Wang, L. (2020). Disentangling stereotypes from social reality: Astrological stereotypes and discrimination in China. Journal of Personality and Social Psychology. https://doi.org/10.1037/pspi0000237 
Maccoby, E. E., \& Jacklin, C. N. (1987). Gender segregation in childhood (Vol. 20, pp. 239287). https://doi.org/10.1016/S0065-2407(08)60404-8

Mackie, J. L. (1974). The cement of the universe: A study of causation. Oxford University Press.

Mandalaywala, T. M., Tai, C., \& Rhodes, M. (2020). Children's use of race and gender as cues to social status. PloS One, 15(6), e0234398. https://doi.org/10.1371/journal.pone.0234398

Markman, K. D., Mizoguchi, N., \& McMullen, M. N. (2008). "It would have been worse under Saddam:" Implications of counterfactual thinking for beliefs regarding the ethical treatment of prisoners of war. Journal of Experimental Social Psychology, 44(3), 650654. https://doi.org/10.1016/j.jesp.2007.03.005

Master, A., Cheryan, S., \& Meltzoff, A. N. (2016). Computing whether she belongs: Stereotypes undermine girls' interest and sense of belonging in computer science. Journal of Educational Psychology, 108(3), 424-437. https://doi.org/10.1037/edu0000061

McCoy, S. K., \& Major, B. (2007). Priming meritocracy and the psychological justification of inequality. Journal of Experimental Social Psychology, 43(3), 341-351. https://doi.org/10.1016/j.jesp.2006.04.009

McLoyd, V. C. (2019). How children and adolescents think about, make sense of, and respond to economic inequality: Why does it matter? Developmental Psychology, 55(3), 592-600. https://doi.org/10.1037/dev0000691

Mehta, C. M., \& Wilson, J. (2020). Gender segregation and its correlates in established adulthood. Sex Roles, 83(3-4), 240-253. https://doi.org/10.1007/s11199-019-01099-9 
Merolla, D. M., Hunt, M. O., \& Serpe, R. T. (2011). Concentrated disadvantage and beliefs about the causes of poverty: A multi-level analysis. Sociological Perspectives, 54(2), 205-227. https://doi.org/10.1525/sop.2011.54.2.205

Mijs, J. J. B. (2018). Inequality is a problem of inference: How people solve the social puzzle of unequal outcomes. Societies, 8(3), 64. https://doi.org/10.3390/soc8030064

Miller, D. I., Nolla, K. M., Eagly, A. H., \& Uttal, D. H. (2018). The development of children's gender-science stereotypes: A meta-analysis of 5 decades of U.S. draw-a-scientist studies. Child Development, 89(6), 1943-1955. https://doi.org/10.1111/cdev.13039

Mistry, R. S., Brown, C. S., Chow, K. A., \& Collins, G. S. (2012). Increasing the complexity of young adolescents' beliefs about poverty and inequality: Results of an 8th grade social studies curriculum intervention. Journal of Youth and Adolescence, 41(6), 704-716. https://doi.org/10.1007/s10964-011-9699-6

Mistry, R. S., Nenadal, L., Griffin, K. M., Zimmerman, F. J., Cochran, H. A., Thomas, C.-A., \& Wilson, C. (2016). Children's reasoning about poverty, economic mobility, and helping behavior: Results of a curriculum intervention in the early school years: Teaching about poverty. Journal of Social Issues, 72(4), 760-788. https://doi.org/10.1111/josi.12193

Nelson, J. C., Adams, G., \& Salter, P. S. (2013). The Marley Hypothesis: Denial of racism reflects ignorance of history. Psychological Science, 24(2), 213-218. https://doi.org/10.1177/0956797612451466

Nolan, D. (2013). Why historians (and everyone else) should care about counterfactuals. Philosophical Studies, 163(2), 317-335. https://doi.org/10.1007/s11098-011-9817-z 
Norton, M. I., \& Sommers, S. R. (2011). Whites See Racism as a Zero-Sum Game That They Are Now Losing. Perspectives on Psychological Science, 6(3), 215-218. https://doi.org/10.1177/1745691611406922

Noyes, A., \& Keil, F. C. (2020). There is no privileged link between kinds and essences early in development. Proceedings of the National Academy of Sciences of the United States of America, 117(20), 10633-10635. https://doi.org/10.1073/pnas.2003627117

Olson, K. R., Shutts, K., Kinzler, K. D., \& Weisman, K. G. (2012). Children associate racial groups with wealth: Evidence from South Africa. Child Development, 83(6), 1884-1899. https://doi.org/10.1111/j.1467-8624.2012.01819.x

Onyeador, I. N., Daumeyer, N. M., Rucker, J. M., Duker, A., Kraus, M. W., \& Richeson, J. A. (2021). Disrupting beliefs in racial progress: Reminders of persistent racism alter perceptions of past, but not current, racial economic equality. Personality and Social Psychology Bulletin, 47(5), 753-765. https://doi.org/10.1177/0146167220942625

Palmer, R. T., Davis, R. J., \& Maramba, D. C. (2010). Role of an HBCU in supporting academic success for underprepared Black males. Cognitive Development, 61, 23.

Panofsky, A., Dasgupta, K., \& Iturriaga, N. (2021). How White nationalists mobilize genetics: From genetic ancestry and human biodiversity to counterscience and metapolitics. American Journal of Physical Anthropology, 175(2), 387-398. https://doi.org/10.1002/ajpa.24150

Perea, J. F. (2015). Doctrines of delusion: How the history of the G.I. Bill and other inconvenient truths undermine the Supreme Court's affirmative action jurisprudence. University of Pittsburgh Law Review, 75(4). https://doi.org/10.5195/lawreview.2014.344 
Peretz-Lange, R. (2021). Why does social essentialism sometimes promote, and other times mitigate, prejudice development? A causal discounting perspective. Cognitive Development, 59, 101085. https://doi.org/10.1016/j.cogdev.2021.101085

Peretz-Lange, R., Harvey, T., \& Blake, P. R. (2022). From "haves" to "have nots": Developmental declines in subjective social status reflect children's growing consideration of what they do not have. Cognition, 223, 105027. https://doi.org/10.1016/j.cognition.2022.105027

Peretz-Lange, R., Perry, J., \& Muentener, P. (2021). Developmental shifts toward structural explanations and interventions for social status disparities. Cognitive Development, 58, 101042. https://doi.org/10.1016/j.cogdev.2021.101042

Phillips, L. T., \& Lowery, B. S. (2018). Herd invisibility: The psychology of racial privilege. Current Directions in Psychological Science, 27(3), 156-162. https://doi.org/10.1177/0963721417753600

Phillips, L. T., \& Lowery, B. S. (2020). I ain't no fortunate one: On the motivated denial of class privilege. Journal of Personality and Social Psychology, 119(6), 1403-1422. https://doi.org/10.1037/pspi0000240

Phillips, L. T., Stephens, N. M., Townsend, S. S. M., \& Goudeau, S. (2020). Access is not enough: Cultural mismatch persists to limit first-generation students' opportunities for achievement throughout college. Journal of Personality and Social Psychology, February. https://doi.org/10.1037/pspi0000234

Pierson, E., Simoiu, C., Overgoor, J., Corbett-Davies, S., Jenson, D., Shoemaker, A., Ramachandran, V., Barghouty, P., Phillips, C., Shroff, R., \& Goel, S. (2020). A large- 
scale analysis of racial disparities in police stops across the United States. Nature Human Behaviour. https://doi.org/10.1038/s41562-020-0858-1

Piff, P. K., Wiwad, D., Robinson, A. R., Aknin, L. B., Mercier, B., \& Shariff, A. (2020). Shifting attributions for poverty motivates opposition to inequality and enhances egalitarianism. Nature Human Behaviour. https://doi.org/10.1038/s41562-020-0835-8

Pratto, F., Sidanius, J., Stallworth, L. M., \& Malle, B. F. (1994). Social dominance orientation: A personality variable predicting social and political attitudes. Journal of Personality and Social Psychology, 67(4), 741-763. https://doi.org/10.1037/0022-3514.67.4.741

Purdie-Vaughns, V., \& Eibach, R. P. (2008). Intersectional invisibility: The distinctive advantages and disadvantages of multiple subordinate-group identities. Sex Roles, 59(56), 377-391. https://doi.org/10.1007/s11199-008-9424-4

Raifman, J., Moscoe, E., Austin, S. B., \& McConnell, M. (2017). Difference-in-differences analysis of the association between state same-sex marriage policies and adolescent suicide attempts. JAMA Pediatrics, 171(4), 350-356. https://doi.org/10.1001/jamapediatrics.2016.4529

Reardon, S. F., Bischoff, K., Owens, A., \& Townsend, J. B. (2018). Has income segregation really increased? Bias and bias correction in sample-based segregation estimates. In Demography (Vol. 55, Issue 6). Demography. https://doi.org/10.1007/s13524-018-0721-4

Reece, R. L., \& O’Connell, H. A. (2016). How the legacy of slavery and racial composition shape public school enrollment in the American South. Sociology of Race and Ethnicity, 2(1), 42-57. https://doi.org/10.1177/2332649215582251 
Rhodes, M., \& Baron, A. (2019). The development of social categorization. Annual Review of Developmental Psychology, 1(1), 359-386. https://doi.org/10.1146/annurev-devpsych121318-084824

Rhodes, M., \& Mandalaywala, T. M. (2017). The development and developmental consequences of social essentialism. Wiley Interdisciplinary Reviews: Cognitive Science, 8(4), 1-18. https://doi.org/10.1002/wcs.1437

Rizzo, M. T., Elenbaas, L., \& Vanderbilt, K. E. (2018). Do children distinguish between resource inequalities with individual versus structural origins? Child Development, 1-17. https://doi.org/10.1111/cdev.13181

Rizzo, M. T., Green, E. R., Dunham, Y., Bruneau, E., \& Rhodes, M. (2021). Beliefs about social norms and racial inequalities predict variation in the early development of racial bias. Developmental Science. https://doi.org/10.1111/desc.13170

Roberts, S. O., \& Rizzo, M. T. (2020). The psychology of American racism. American Psychologist. https://doi.org/10.1037/amp0000642

Roese, N. J., \& Epstude, K. (2017). The functional theory of counterfactual thinking: New evidence, new challenges, new insights. In Advances in Experimental Social Psychology (Vol. 56, pp. 1-79). Elsevier. https://doi.org/10.1016/bs.aesp.2017.02.001

Rucker, J. M., \& Richeson, J. A. (2021). Toward an understanding of structural racism: Implications for criminal justice. Science, 374(6565), 286-290. https://doi.org/10.1126/science.abj7779

Salter, P. S., Adams, G., \& Perez, M. J. (2018). Racism in the structure of everyday worlds: A cultural-psychological perspective. Current Directions in Psychological Science, 27(3), 150-155. https://doi.org/10.1177/0963721417724239 
Santhanagopalan, R., Heck, I. A., \& Kinzler, K. D. (2022). Leadership, gender, and colorism: Children in India use social category information to guide leadership cognition. Developmental Science. https://doi.org/10.1111/desc.13212

Seiver, E., Gopnik, A., \& Goodman, N. D. (2013). Did she jump because she was the big sister or because the trampoline was safe? Causal inference and the development of social attribution. Child Development, 84(2), 443-454. https://doi.org/10.1111/j.14678624.2012.01865.x

Shtulman, A., \& Schulz, L. (2008). The relation between essentialist beliefs and evolutionary reasoning. Cognitive Science, 32(6), 1049-1062. https://doi.org/10.1080/03640210801897864

Shultz, T. R. (1982). Rules of causal attribution. Monographs of the Society for Research in Child Development, 47(1), 1. https://doi.org/10.2307/1165893

Shutts, K. (2015). Young children's preferences: Gender, race, and social status. Child Development Perspectives, 9(4), 262-266. https://doi.org/10.1111/cdep.12154

Sidanius, J., Hudson, S. T. J., Davis, G., \& Bergh, R. (2018). The theory of gendered prejudice: A social dominance and intersectionalist perspective. In A. Mintz \& L. Terris (Eds.), The Oxford Handbook of Behavioral Political Science. Oxford University Press. https://doi.org/10.1093/oxfordhb/9780190634131.013.11

Sigelman, C. K. (2012). Rich man, poor man: Developmental differences in attributions and perceptions. Journal of Experimental Child Psychology, 113(3), 415-429. https://doi.org/10.1016/j.jecp.2012.06.011 
Sobel, D. M., Tenenbaum, J. B., \& Gopnik, A. (2004). Children's causal inferences from indirect evidence: Backwards blocking and Bayesian reasoning in preschoolers. Cognitive Science, 28(3), 303-333. https://doi.org/10.1207/s15516709cog2803_1

Soylu Yalcinkaya, N., Estrada-Villalta, S., \& Adams, G. (2017). The (biological or cultural) essence of essentialism: Implications for policy support among dominant and subordinated groups. Frontiers in Psychology, 8(MAY), 1-10. https://doi.org/10.3389/fpsyg.2017.00900

Spelke, E. S. (2005). Sex differences in intrinsic aptitude for mathematics and science? A critical review. American Psychologist, 60(9), 950-958. https://doi.org/10.1037/0003066X.60.9.950

Spencer, Q. (2019). I-A more radical solution to the race problem. Aristotelian Society Supplementary Volume, 93(1), 25-48. https://doi.org/10.1093/arisup/akz011

Sunstein, C. R. (2016). Historical explanations always involve counterfactual history. Journal of the Philosophy of History, 10(3), 433-440. https://doi.org/10.1163/18722636-12341345

Vasilyeva, N., Gopnik, A., \& Lombrozo, T. (2018). The development of structural thinking about social categories. Developmental Psychology, 54(9), 1735-1744. https://doi.org/10.1037/dev0000555

Vasilyeva, N., Gopnik, Alison, \& Lombrozo, T. (2021). Beyond situational explanations: Structural thinking as a unique type of externalist thinking. Society for Research in Child Development.

Vasilyeva, N., \& Lombrozo, T. (2020). Structural thinking about social categories: Evidence from formal explanations, generics, and generalization. Cognition, 204(October 2019), 104383. https://doi.org/10.1016/j.cognition.2020.104383 
Vishkin, A. (2022). Queen's gambit declined: The gender-equality paradox in chess participation across 160 countries. Psychological Science, 095679762110348. https://doi.org/10.1177/09567976211034806

Walker, D. E., Smith, Kevin A, \& Vul, Edward. (2015). The "Fundamental Attribution Error" is rational in an uncertain world. Proceedings of the 37th Annual Conference of the Cognitive Science Society, 6. http://www.evullab.org/pdf/walker_cogsci2015_final.pdf

Wasserman, E. A., \& Berglan, L. R. (1998). Backward blocking and recovery from overshadowing in human causal judgement: The role of within-compound associations. The Quarterly Journal of Experimental Psychology: Section B, 51(2), 121-138. https://doi.org/10.1080/713932675

Weiner, B. (1985). An attributional theory of achievement motivation and emotion. Psychological Review, 92(4), 548-573. https://doi.org/10.1037/0033-295X.92.4.548

Weiner, B., Osborne, D., \& Rudolph, U. (2011). An attributional analysis of reactions to poverty: The political ideology of the giver and the perceived morality of the receiver. Personality and Social Psychology Review, 15(2), 199-213. https://doi.org/10.1177/1088868310387615

Weisgram, E. S., \& Bigler, R. S. (2007). Effects of learning about gender discrimination on adolescent girls' attitudes toward and interest in science. Psychology of Women Quarterly, 31(3), 262-269. https://doi.org/10.1111/j.1471-6402.2007.00369.x

Weiss-Gal, I., Benyamini, Y., Ginzburg, K., Savaya, R., \& Peled, E. (2009). Social workers' and service users' causal attributions for poverty. Social Work, 54(2), 125-133. https://doi.org/10.1093/sw/54.2.125 
Wendell, J. (2020). Qualifying counterfactuals: Students' use of counterfactuals for evaluating historical explanations. History Education Research Journal, 17(1), 50-67. https://doi.org/10.18546/HERJ.17.1.05

Wilkerson, I. (2010). The warmth of other suns: The epic story of America's Great Migration. Random House.

Wilkerson, I. (2020). Caste: The origins of our discontents. Random House.

Wood, W., \& Eagly, A. H. (2002). A cross-cultural analysis of the behavior of women and men: Implications for the origins of sex differences. Psychological Bulletin, 128(5), 699-727. https://doi.org/10.1037/0033-2909.128.5.699

Woodward, J. (2005). Making things happen: A theory of causal explanation. Oxford University Press.

Yang, X., Naas, R., \& Dunham, Y. (2021). Testing the limits of structural thinking about gender. Developmental Science. https://doi.org/10.1111/desc.13169

Yavorsky, J. E., Kamp Dush, C. M., \& Schoppe-Sullivan, S. J. (2015). The production of inequality: The gender division of labor across the transition to parenthood. Journal of Marriage and Family, 77(3), 662-679. https://doi.org/10.1111/jomf.12189

Yeager, D. S., Purdie-Vaughns, V., Hooper, S. Y., \& Cohen, G. L. (2017). Loss of institutional trust among racial and ethnic minority adolescents: A consequence of procedural injustice and a cause of life-span outcomes. Child Development, 88(2), 658-676. https://doi.org/10.1111/cdev.12697

Zucker, G. S., \& Weiner, B. (1993). Conservatism and perceptions of poverty: An attributional analysis. Journal of Applied Social Psychology, 23(12), 925-943. https://doi.org/10.1111/j.1559-1816.1993.tb01014.x 


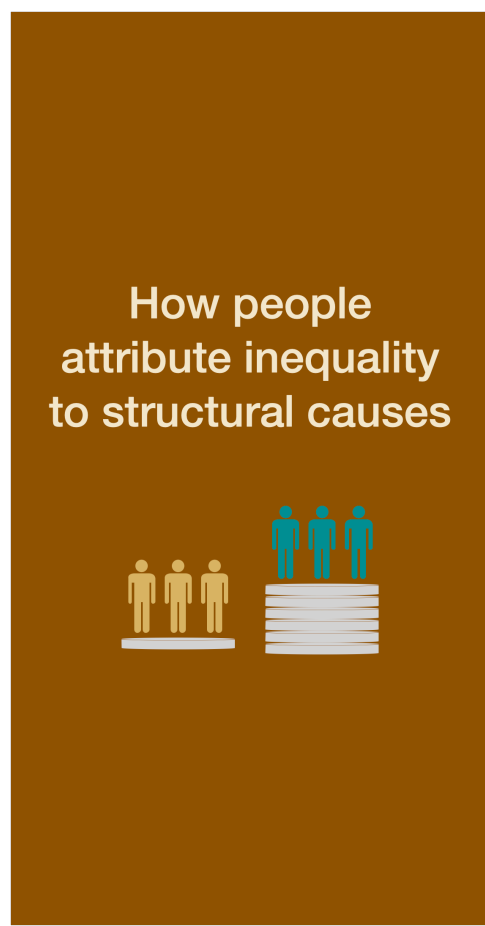

Awareness of structural constraints is not enough; people need to see those factors as difference-making:

$\Delta$ Within-group change

The disadvantaged group's outcomes improve under better societal conditions

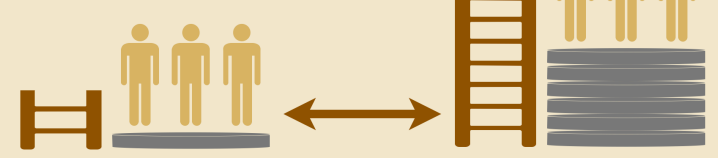

$\Delta$ Between-group comparison

The advantaged group, who has similar baseline intrinsic traits to the disadvantaged group, experiences more favorable societal conditions and outcomes

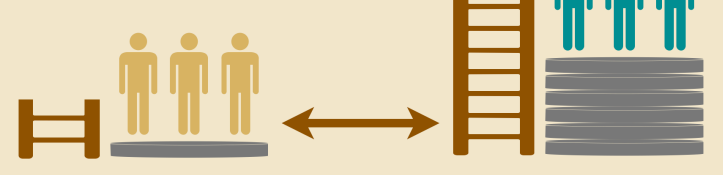

Figure 1. Overview of the difference-making framework of structural causal attribution. 